\title{
Ignacio Manuel Altamirano (1834-1893): mediador cultural de la vida literaria (México: 1867-1889) ${ }^{1}$
}

\author{
Gustavo Adolfo BEDOYA SÁNCHEZ ${ }^{2}$ \\ Universidad de Antioquia, Colombia \\ gustavoadolfo00@yahoo.com
}

\begin{abstract}
RESUMEN
Este ensayo examina las características culturales que posibilitaron la vida literaria mexicana de mediados y finales del siglo XIX. Se centra en la figura de Ignacio Manuel Altamirano como crítico y promotor de las instituciones literarias de la época, a saber: las tertulias y cofradías, las publicaciones periódicas, la edición de libros, la traducción y lectura crítica de la literatura, en últimas, la especialización del escritor y la formación del lector, todo ello bajo los parámetros del nacionalismo liberal mexicano, durante el periodo conocido como Reforma.
\end{abstract}

Palabras clave: liberalismo, nacionalismo, periodismo, literatura, México.

Ignacio Manuel Altamirano (1834-1893): cultural mediator of the literary life (México: 1867-1889)

\begin{abstract}
This essay examines the cultural characteristics that enabled the Mexican literary life of mid to late nineteenth century. It focuses on the figure of Ignacio Manuel Altamirano as a critic and promoter of the literary institutions of the time, namely, the gatherings and
\end{abstract}

${ }^{1}$ Este ensayo se deriva de la investigación El crítico de lo cultural en las publicaciones periódicas de 1900 a 1960. Una forma histórica del intelectual colombiano (2013-2016), ejecutado con recursos de la Convocatoria de proyectos de investigación de Ciencias Sociales, Humanidades y Artes 2012, financiada por el Comité para el Desarrollo de la Investigación (CODI) de la Universidad de Antioquia; también se inscribe en el marco de la Estrategia de sostenibilidad para grupos de investigación CODI 2013-2014. La indagación bibliográfica en el Instituto Iberoamericano de Berlín (IBI), fue realizada gracias a la Beca para estancias de investigación concedida en el 2011 por el Servicio Alemán de Intercambio Académico (DAAD).

${ }^{2}$ Miembro del Grupo de Investigación Colombia: tradiciones de la palabra (CTP) de la Universidad de Antioquia. Más información acerca del grupo de investigación: http://ihlc.udea.edu.co/ 
brotherhoods, periodicals, book publishing, translation and critical reading of the literature, in the end, the specialization of the writer and reader training, all under the parameters of liberal nationalism Mexico, during the period known as the Reforma.

Key words: liberalism, nationalism, journalism, literature, México.

SUMARIO: 1.Apuntes para una biografía intelectual. 2.Vida literaria mexicana: cenáculos y veladas. 3.Publicaciones periódicas. 4.Edición y lectura crítica de la literatura. 5.Traducción y universalismo literario 6.La historia literaria y la idea de nación: el caso de la novela 7.Palabras finales.

Rafael Gutiérrez Girardot, en Temas y problemas de una historia social de la literatura hispanoamericana (1989), expone los inconvenientes teóricos y metodológicos de escritura de una historia social de la literatura. Primero, hace referencia a la dificultad de "transponer" al contexto latinoamericano la propuesta teórica de Annales o el grupo en torno a Kosselleck (ambos considerados momentos de insuperable valor metodológico), ya que ellos mismos teorizaron muy poco en torno a sus trabajos. Segundo, exhibe la necesidad de investigaciones comparativas entre las sociedades americanas y europeas, las cuales -asegura el autor- han sido escasas. Y tercero, establece la necesidad de contar con las fuentes históricas para construir la "vida literaria", fuentes que resultan casi inaprehensibles por su cantidad, su diversidad y la dificultad de hallarlas en un solo archivo. De esta manera, Gutiérrez dicta: "Describir la vida literaria, esto es, la red de preparación, producción y recepción de la literatura, resulta desde este punto de vista material casi impracticable" (20. El subrayado es nuestro). Lo anterior no es obstáculo para que el colombiano proponga una salida: Gutiérrez exige la comprensión de la relación literatura y sociedad desde la concepción de "mediación" y no de "reflejo": la mediación evidencia el momento en que las ideologías sociales se imponen en las obras artísticas, lo que conlleva el análisis, no solo del escritor y su obra (como lo ha hecho la historiografía literaria tradicional), sino también el análisis de los lectores, productores y medios de difusión de lo literario, es decir, de los salones, tertulias, cafés, imprentas, editoriales, librerías y bibliotecas públicas y privadas...; en últimas, el análisis de lo que el autor llama "institución" literaria (30).

Así, analizar esta institución, en aras de describir la vida literaria parece también una tarea mayúscula. Sin embargo, para el contexto mexicano de mediados y finales del siglo XIX, la figura de Ignacio Manuel Altamirano recoge la personalidad de lo que hoy en día se denominaría un mediador cultural, un promotor, que durante gran parte de su vida como hombre de letras se dedicó a dejar constancia expresa de la realidad literaria del continente, y de las necesidades de modernización de la propia literatura de su país (con la cual él mismo contribuyó); de esta manera, la descripción de Altamirano como intelectual permite el re-conocimiento de la vida literaria mexicana, de mediados y finales del siglo XIX, durante el periodo conocido en la historiografía tradicional como Reforma. 


\section{Apuntes para una biografía intelectual}

Altamirano nació el 13 de noviembre de 1834 en Tixtla, una pequeña ciudad perteneciente al Estado de Guerrero, de pocas construcciones arquitectónicas y poblada mayormente por indígenas. Su familia había adoptado el apellido de un español que bautizó a uno de sus antepasados. Su niñez la pasó entre las labores del campo, y solo en 1846, a la adelantada edad de 12 años, y cuando apenas empezaba a hablar español, Altamirano ingresó a la escuela de la municipalidad, en la que se dividían a los estudiantes en "niños de razón" e "indígenas". Los últimos aprendían catecismo pero no a leer ni a escribir, además, era costumbre reprenderlos físicamente. Afortunadamente, el padre de Altamirano fue nombrado alcalde del pueblo para los indígenas (realmente un cargo menor), lo que hizo que el profesor de la escuela admitiera al niño entre los "privilegiados" (Véase González 1936; Reyes Nevares 1959 y Ruiz 1976).

El 9 de enero de 1849 se promulgó el Decreto número 112, por el cual el Estado de México ofrecía becas para "alumnos de municipalidad" en el Instituto Literario de Toluca (en ese entonces el colegio de mayor prestigio del Estado). Los aspirantes debían pertenecer a una localidad, no tener recursos económicos para estudiar, además de disposiciones para el estudio y no superar los 12 años. Altamirano fue aceptado a pesar de tener 14, y por poco no alcanza a llegar físicamente al Instituto, ya que su familia no contaba con los recursos para enviarlo. Para entonces, fue el viaje más largo que el joven había hecho en su vida ${ }^{3}$.

Altamirano llegó al Instituto el 17 de mayo de 1849 y fue rechazado por el rector Felipe Sánchez Solís al superar la edad máxima permitida, asimismo, el rector exigió más dinero por su manutención. Biógrafos como Batis (1963) y Ruiz (1976) creen que la negativa se debió a que el joven Altamirano venía de una municipalidad que pensaba dejar el Estado de México para conformar el de Guerrero. El municipio de Tixtla protestó airadamente y extendió su queja al Gobernador, obteniendo positivamente la resolución del problema ${ }^{4}$.

${ }^{3}$ Según el Decreto, cada municipalidad debía enviar al Instituto a un indígena y pagar de su fondo 16 pesos mensuales. Por su parte, el Instituto cubriría el alojamiento, la alimentación, el vestido y los libros. La ley había sido inspirada por el reconocido pensador Ignacio Ramírez, "El Nigromante", quien posteriormente se convertirá en amigo y guía intelectual de Altamirano. En reconocimiento a dicha amistad, Altamirano escribirá la biografía póstuma de su maestro, en febrero de 1889. Altamirano apuntó: "Ignacio Ramírez influyó en mi existencia de una manera radical, y yo lo consideré siempre, no como un amigo, lo cual habría establecido entre nosotros una especie de igualdad, sino como un padre, como un maestro, ante quien me sentía penetrado de profundo respecto y de sincera sumisión" (1988b: 102).

4 El Instituto pertenecía al Estado de México, uno de los más importantes para la Federación. El Estado fue creado en 1824, dirigido por Lorenzo de Zavala desde 1827, quien creó la primera Constitución Política. Ese mismo año reorganizó las leyes coloniales 
Todos los estudiantes debían madrugar a orar y entonar himnos religiosos, muchos de ellos en latín. Luego debían ir a misa, pasar al refectorio y a la academia musical para clases de piano o flauta. Las clases, propiamente hablando, se constituían de cursos de latín, matemáticas, sintaxis, prosodia y ortografía. De último quedaban los cursos abstractos, tales como la física. De un aparente corte colonial, la educación en el Instituto no se detenía tan solo en la instrucción clásica; para 1851, por ejemplo, mientras Altamirano realizaba sus estudios, se le dio cabida a los cursos de comercio, industria y agricultura. Además, la nómina de profesores contaba con una serie de reconocidos estudiosos de diversas disciplinas académicas. No había golpes pero sí otra serie de castigos humillantes, tales como "hincadas", "vestido burdo" y aislamiento con ayuno. También había expulsión para aquellos estudiantes "incorregibles".

Como en la escuela, en el Instituto se dividían a los estudiantes, ahora entre pobres y ricos. Sin embargo, Altamirano se distinguió académicamente, incluso por encima de sus compañeros "afortunados", tan así que para 1850 estaba integrado al Instituto: ese año empezó a estudiar francés y a hacer gala de lo propio en la traducción de fragmentos selectos; también fue llamado a sustentar su examen de forma pública (lo cual solo lo hacían los estudiantes aventajados), y finalmente, ese mismo año fue nombrado bibliotecario del Instituto, labor que ejecutó hasta 1852. La permanencia en el Instituto y sobre todo sus labores en la Biblioteca son de suma importancia en su formación intelectual, ya que tuvo al alcance los libros imprescindibles para su preparación: escritores y pensadores mexicanos y extranjeros, los cuales le proporcionaron una sólida cultura, lo que él siempre apreciará como un "valioso tesoro".

que aún estaban establecidas como lastres, y coordinó la creación del Instituto Literario en Tlalpan, en ese entonces capital del Estado. En el Instituto las materias más importantes eran derecho canónico y latín, derecho civil y constitucional, economía política, matemáticas, gramática castellana, francés y academia de dibujo (todas involucraban altos conceptos religiosos). En 1830 Zavala dejó el poder a Melchor Múzquiz, conservador, quien trasladó el Instituto a la nueva capital del Estado: Toluca. Tres años después Zavala regresó a la dirección del Estado y del Instituto. Nombró como director del último al liberal José María González Arratia. Cuando cayó el federalismo, el centralismo suprimió el Instituto, por lo menos hasta la Constitución de 1824, cuando Francisco Modesto de Olaguíbel asumió las riendas del Estado. Bajo su gobierno se restableció el Instituto en 1847 y su dirección fue encomendada al maestro Felipe Sánchez Solís. Para el momento en que llega Altamirano se agregan al plan de estudios las cátedras de física, inglés, lógica, también una academia de música y educación física.

${ }^{5}$ La biblioteca había sido trasladada junto con el Instituto (como ya se ha dicho) desde Tlapan. La biblioteca fue fundada también por Lorenzo de Zavala. Se sabe con seguridad que uno de los primeros fondos de dicha biblioteca fueron los autores enciclopedistas solicitados por el propio fundador: Cándido de Voltaire, Emilio de Rousseau y Contrato 
Para 1851 Altamirano compuso y leyó públicamente algunos poemas románticos, asimismo, expuso una talla de un crucifijo en marfil; es de anotar que Toluca poseía una población en su mayoría católica y que Altamirano nunca abandonó la religión del todo, aunque tampoco intervino con fuerza en su ideología ${ }^{6}$. Aprendió francés e inglés, lo cual también demostró en examen público. Sus conocimientos en latín lo llevaron a traducir fragmentos de la obra de Cicerón, Horacio, Fedro, Plutarco y Cornelio Nepote. Por estos años el autor se relacionó activamente con el universalismo en las letras, gracias a la lectura que hizo de autores ingleses, tales como Dickens, Shakespeare, Logfellow y Cooper.

En el Instituto conoció a su benefactor Ignacio Ramírez, "El Nigromante", quien lo invitó a pertenecer a sus clases de latinidad, a pesar de ser un estudiante de grado inferior. Fue "El Nigromante" quien le ayudó a comprender el drama de la nación mexicana y la urgencia de la intervención de los intelectuales comprometidos con la lucha liberal, primero de la Reforma y luego bajo la dirección de Benito Juárez contra la intervención francesa. Los domingos, en lugar de pasear, Altamirano asistió a las cátedras libres de "Bella literatura" en las que el maestro advirtió la aguda cultura del estudiante. Lo anterior hizo que ambos se hicieran amigos, junto con los hermanos Mateos. El profesor aprovechó toda oportunidad para hablar de política, lo que ocasionó su retiro del Instituto, pero para entonces el maestro ya había logrado la creación de una pequeña comunidad académica ${ }^{7}$.

Una vez el Estado de Guerrero se conformó, Tixtla dejó de enviar los recursos para sus estudiantes; pero el rector del colegio, Felipe Sánchez Solís, que al

social de Montesquieu. También se sabe que la biblioteca tenía las obras de Gibbon, Llorente, Bacon, Robertson, Thiers, Segur, Smollet, Bentham y Filangieri. La censura de la corona española durante tiempos coloniales, que rehusaba el ingreso de literatura francesa, solo acrecentó la afición por buscar y leer estos materiales durante gran parte del siglo XVIII y XIX, hasta que en época de la Independencia ingresaron, sin problemas, las obras de Voltaire, Rousseau y Diderot. Para mediados del siglo XIX conocer a Hugo, Lamartine, Saint Pierre y otros románticos era algo normal. Asimismo, conocer las obras de los italianos Alfieri y Manzoni; y las obras de los ingleses Scott y Milton. En contraposición, era poco lo que se conocía de Alemania y su cultura literaria y filosófica (Batis, 1963).

${ }^{6}$ La obra poética del autor está recogida en Altamirano (1986), sobre su relación con la religión, véase: Altamirano (1995).

7 Acerca de la enseñanza de su maestro, en la ya señala biografía que realizó de él, Altamirano dice: "Era en toda la amplitud de la palabra, una enseñanza enciclopédica, y los que la recibimos aprendimos más en ella, que lo que pudimos aprender en el curso entero, de los demás estudios. Allí se formó nuestro carácter, allí aceptamos nuestro credo político al que hemos sido fieles sin excepción de una sola individualidad. Porque es de advertirse, y es una cosa notable ciertamente, que ni un solo discípulo de Ramírez, en el Instituto, ha renegado de los principios liberales y filosóficos que les inculcó el maestro, sino que, al contrario, todos los han sellado con su constancia y con sus obras, y algunos con su sangre" (1988b: 126). 
principio quiso por fuera de la institución al joven Altamirano, le había tomado tal aprecio que consintió su estadía. Sin embargo, el estudiante debió retirarse en 1852 al dar a conocer sus ideas en contra del Gobierno, en el periódico Los Papachos.

Para el momento en que Altamirano dejó el Instituto manejaba bastante bien, además del español, el francés. En estos momentos se inició la etapa menos conocida del autor. Se supone, por ejemplo, que dictó clases de francés en colegios particulares a cambio de comida y alojamiento; también que fue profesor de primeras letras y escritor de obras teatrales para compañías ambulantes, es el caso de la escritura de Mórelos en Cuautla ${ }^{8}$.

Para 1854, a los 20 años, Altamirano empezó a cursar Derecho en el Colegio de San Juan de Letrán de la Ciudad de México. Suspendió las clases ante la sublevación del pueblo, en lo que se conoció como Revolución de Ayluta (Estado de Guerrero). La idea central de la misma era derribar al presidente-dictador Antonio López de Santa Anna. El pueblo, sobre todo los jóvenes, acudieron al llamado y en este primer combate Altamirano peleó bajo las órdenes del general y amigo Juan Álvarez. Una vez Santa Anna renunció al cargo de presidente, Altamirano dejó las armas y reanudó sus estudios.

Para 1858, y ante diversos intentos de los vencidos por volver al poder, Altamirano (de tan solo 24 años de edad), conformará junto con sus compañeros Juan Díaz Covarrubias, Manuel Mateos, Alfredo Chavero y Manuel M. Flores, un grupo en contra de los vencidos. Los integrantes se reunían en el cuarto de Altamirano a discutir ideas políticas, a leer versos románticos y pronunciar discursos patrióticos. Asimismo, acudían a la Cámara de Diputados a apoyar ruidosamente los discursos políticos de los simpatizantes, entre ellos Melchor Ocampo, Francisco Zarco y "El Nigromante". Se da inicio a la Guerra de Tres Años (1858-1860), con algunas victorias por parte de los conservadores. Altamirano y sus amigos atacan con folletos y hojas sueltas impresas secretamente. Sin embargo, asesinan a Covarrubias y a Mateos, lo que hizo que el resto del grupo tomara las armas en 1859, año en que Altamirano recibió su título de abogado, a los 25 años de edad.

La guerra finalizó en 1860 bajo la orden de Benito Juárez, el cual logró la victoria para los liberales. De esta manera entraron triunfantes a la Ciudad de México, en la que se estableció el gobierno y se pensó en la reorganización del país. Altamirano fue nombrado diputado por el distrito de Chilapa; sin embargo, los vencidos pidieron a Napoleón III invadir México para establecer un imperio. Y por ello, en 1862 (a los 28 años cumplidos de Altamirano), los franceses entran a México por el puerto de Veracruz y avanzan hacia Puebla, donde son vencidos por el general Ignacio Zaragoza. En 1863 los liberales vuelven a enfrentar a los

${ }^{8}$ Sobre la dificultad de establecer la biografía de Altamirano en esta época, véase a Girón (1997), quien presenta de manera novedosa algunos datos sobre el tema. 
franceses y Altamirano recibe del presidente Juárez el nombramiento de Coronel Auxiliar de la Guardia Nacional. Los liberales cayeron ante los invasores: primero Puebla, luego incluso Ciudad de México, así que huyen para no ser atrapados. El emperador Maximiliano y su esposa Carlota intentaron organizar el imperio desde Ciudad de México, lo que se les dificultó ya que ni Benito Juárez ni sus seguidores dejaron de luchar, una vez reagrupados.

Los liberales intentaron instalar el Congreso en San Luis de Potosí, pero ante las dificultades y los acosos de los invasores decidieron viajar a lugares más seguros. Altamirano atravesó Zacatecas, Jalisco, Durango, Sinaloa, puerto de Mazatlán (donde se encontró con "El Nigromante"), luego viajó junto con Alfredo Chavero a bordo de la goleta "Colima" hasta Acapulco. Allí se puso a las órdenes del general Álvarez. De nuevo combatió como soldado en la parte norte de Guerrero, pasó por Morelos hasta Toluca, donde se unió a las fuerzas del general Vicente Jiménez y marchó hacia Querétaro, donde se libró la batalla decisiva, haciendo victoriosos a los republicanos: Maximiliano fue fusilado ${ }^{9}$. Luego de Querétaro, Altamirano viajó a ciudad de México donde vio a Juárez restablecer el gobierno. Es en ese momento, una vez terminada la guerra, cuando Altamirano emprenderá sus actividades en pro de la vida cultural mexicana, sobre todo de la vida literaria.

\section{Vida literaria mexicana: cenáculos y veladas ${ }^{10}$}

Altamirano dedicó gran parte de su tiempo y recursos a 'crear' la vida cultural, literaria, del México de mediados y finales del siglo XIX. No sólo organizó a los intelectuales y escritores en cenáculos, también organizó tertulias y sociedades artísticas y científicas. Fundó periódicos y revistas, en donde encontró el medio para defender la novela como el género literario que, comprometido con la idea de Nación, adelantaría la sociedad hacia su "progreso". Como hombre de letras se destacó en la escritura literaria, en el periodismo y también en la tribuna y la cátedra. A cada una de sus labores le imprimó un fuerte acento crítico que representa al día de hoy una de las singularidades más importantes de su obra.

El 4 de diciembre de 1867, luego de presenciar una obra teatral, Ignacio Manuel Altamirano, de 33 años, y algunos de sus amigos, conversan airadamente sobre el presente literario de México. La conversación la finalizan en la casa de Altamirano

9 Sobre la vida militar de Altamirano, véase: Sánchez (1964). Asimismo, sobre la historia política mexicana se puede consultar al propio Altamirano, en su libro Historia y política de México (1821-1882) (1958).

10 Altamirano dejó constancia de las veladas literarias en los documentos: "Revistas literarias de México", publicadas en el folletín La Iberia, México, 30 de junio a 4 de agosto de 1868; y en: "La quinta velada literaria", publicado en El Renacimiento, No 1, México, 2 de enero de 1869. De ambas publicaciones existen diversas reediciones a manera de folletín, artículo de prensa, antología y libro. Se citará la edición de más fácil adquisición en los medios contemporáneos, a saber: las obras completas de Altamirano: 1988a. 
una vez se percatan de lo tarde que se les ha hecho. De esta manera queda instaurada la primera de las veladas literarias. La reunión se llevó a cabo sin ningún guión o formalismo planificado. La mayoría de los asistentes eran jóvenes pertenecientes a ambos partidos políticos (que ya estaban acostumbrados a visitar la casa de Altamirano ante requerimientos propios), así, la confluencia de personas de diferentes credos políticos hizo pensar en las reuniones como ejemplo de fraternidad y libre pensamiento.

Altamirano dio noticia de seis veladas más: las dos primeras presididas en las casas de Riva Palacio y Martínez de la Torre. Luego la que se llevó a cabo en la casa de Alfredo Chavero (organizada por este último y Juan A. Mateos) y la de Ignacio Ramírez y Agustín Siliceo. Las últimas dos veladas se llevaron a cabo en casa de Schiafino y en la casa de Riva Palacio, otra vez. Sin embargo, Batis (1963) señala que Altamirano sólo contó las seis veladas en las que el centro de la reunión fue, enteramente, lo literario, pero que otros testigos presenciales llegaron a contar un poco más de dieciocho veladas.

Para junio de 1868 Altamirano anunció que las Veladas literarias debían suspenderse ante el auge del teatro. Sin embargo, anunció con orgullo: las veladas reaparecerán pronto porque tienen "todos los elementos de vida propia que se necesitan para que una institución se establezca y prospere" (1988a, 111). En términos materiales, las veladas se organizaban en la casa de uno de los agregados, se preparaban comidas y bebidas, incluso en muchas ocasiones se acompañó el encuentro con música de piano. Siempre se llevaron a cabo en horas de la noche y finalizaban en la madrugada. Los salones en los que se organizaron las reuniones estabas lujosamente decorados, hasta algunos que oficializaban el acto sacaban a relucir libros costosos y escasos. Justamente ese ambiente de lujo alejó a los integrantes más pobres que no podían, materialmente, organizar uno de los encuentros. Altamirano, que siempre fue llamado "maestro" en estas cofradías, por encima de toda condición de ostentación buscó "estimular a la juventud" (111), lo que hizo evidente cuando solicitó que en lugar de gastar dinero en la organización se destinaran dichos recursos para la publicación de las obras leídas en las reuniones, una vez finalizada la etapa de corrección de las mismas. Lo anterior se hizo realidad con la publicación de Cuadernos de las Veladas (149). Para Altamirano, dichas publicaciones representaron la "protección verdadera" que necesitaba la literatura producida por los "jóvenes autores", acostumbrados a guardar "sus manuscritos por falta de medios para publicarlos" $(152)^{11}$. Asimismo,

11 Martínez, en Altamirano (1988a), habla de la publicación de una serie de textos denominados Veladas literarias. Colección de poesías leídas por sus autores en una reunión de poetas mexicanos, en los años 1867 y 1868. Por desgracia, para esta investigación solo se contó con las referencias de Altamirano en sus obras y las muestras que reprodujo en los medios periódicos de difusión de la época. 
en las veladas se llevaron a cabo diversas traducciones para los no entendidos, traducciones que luego fueron recogidas en El Renacimiento, revista literaria fundada por Altamirano en 1867, considerada uno de los medios periódicos más importantes de la época. Finalmente, Altamirano estableció por escrito que aquellas veladas produjeron "un movimiento intelectual notable" (152). En términos reales, las veladas fueron el espacio donde se dieron a conocer las obras de autores noveles (tales como Gonzalo A. Esteva, Esteban González Verástegui, Manuel Sánchez Facio, J. Rivera y Río, Joaquín Téllez, José María Ramírez, Julián Montiel), pero sobre todo, la obra de autores de la talla de Alfredo Chavero, Justo Sierra y Guillermo Prieto, entre otros. Las veladas deben ser vistas como los espacios que en la época permitieron la creación literaria, la crítica y evaluación de lo extranjero, y sobre todo, la discusión acerca del trabajo intelectual que la nueva generación emprendía, justamente la nueva generación que buscaba crear Altamirano. De esta manera, las veladas deben pensarse como el germen de la institucionalización literaria de mediados del siglo XIX mexicano.

Antes de que las veladas finalizaran, el 24 de abril de 1868, los bohemios se organizaron para formar la Sociedad Netzahualcóyotl (rey nahua arquetipo de cultura). Algunas de las producciones del grupo fueron publicadas en el diario El Siglo XIX y El Renacimiento. En estas reuniones se leía a Campoamor, Hugo, y se empezaba a leer a Núñez de Arce y a Bécquer. Asimismo, se prestó mucha atención al positivismo de Barreda. ${ }^{12}$ A la sociedad también asistieron algunas mujeres, esposas de intelectuales; y aunque las penurias económicas de los integrantes eran bastantes, para 1875 había 130 socios activos y 70 "protectores"13.

\section{Publicaciones periódicas}

Como la mayoría de los autores del siglo XIX, Altamirano era un "publicista", es decir, un hombre dedicado a la escritura literaria y al periodismo en general. $\mathrm{Su}$

12 Alumno de Comte en el Palais Royal, fue llamado por Juárez para organizar la Preparatoria en México. En los años de Reforma el Gobierno se propuso organizar una clase científica dirigente que formara al pueblo desde el positivismo.

${ }^{13}$ En el aspecto científico es de resaltar la conformación de la Sociedad Mexicana de Geografía y Estadística, la Sociedad de Historia Natural, la Academia de Medicina, la Sociedad Pedro Escobelo y la Sociedad Andrés del Río, la primera dedicada a la medicina y la segunda a la minería. De entre todas, hay que subrayar la Sociedad Mexicana de Geografía y Estadística, fundada en 1833, tercera en su género en el mundo entero, estuvo encargada de publicar un Boletín que para el año 1882 ya había coleccionado 22 volúmenes. La Sociedad estaba protegida por el gobierno y recibía una subvención de 4.000 pesos anuales. Poseía una biblioteca, abierta desde 1872, de más de 1.000 volúmenes. De todas estas sociedades da cuenta Altamirano en sus reseñas y notas periodísticas, asimismo, ayudó en la conformación de ellas, hizo parte activa de sus investigaciones y usó sus instalaciones y archivos. 
obra se inscribía dentro de un partido político y además, se publicaba en uno de sus medios de comunicación, exactamente un diario o una revista. Con el tiempo, muchos de estos materiales se recogían y se publicaban en formato libro.

Altamirano fundó, junto con muchos de sus compañeros de tertulia, sobre todo con Guillermo Prieto, diversos diarios y revistas; de entre todos ellos sobresalen: $E l$ Correo de México (1867), El Renacimiento (1867), El Federalista (1871), La Tribuna (1875) y La República (1880). Al mismo tiempo, Altamirano colaboró intensamente en El Siglo XIX, El Domingo, El Artista y El Semanario Ilustrado. Esta constante labor en pro de las "bellas letras" lo postula, más que como un fortalecedor de la literatura nacional, en su propio creador. Recuérdese la importancia de las publicaciones periódicas para la existencia material de lo literario durante los siglos XVIII y XIX en Hispanoamérica, incluso adelantado el siglo XX, el periódico era una de las formas más económicas y eficaces de promocionar lo literario. Así, independientemente de la existencia de la literatura mexicana durante mediados y finales del XIX, es en la labor crítica de Altamirano donde se presenta de manera sistémica el inventario de lo adelantado en materia literaria, y la necesidad de su posterior desarrollo. Desde la columna periodística Altamirano señaló a la nueva generación y le marcó su itinerario.

De todos sus empeños, el de mayor importancia para la actualidad, desde el punto de vista literario, es el coronado con el título El Renacimiento, el intento más claro por unificar a todos los literatos de la época, independientemente de su filiación ideológica, en donde la controversia política y religiosa no debía tener espacio, según palabras del propio Altamirano en el prospecto de la publicación. En esa misma introducción, escrita el 2 de enero de 1869, Altamirano (1988b) declara la finalidad de la misma:

Con el objeto, pues, de que haya en la capital de la República un órgano de estos trabajos [los trabajos literarios producidos por los jóvenes], un foco de entusiasmo y de animación para la juventud estudiosa de México, hemos fundado este periódico. La misma familia literaria que estableció las primeras reuniones el año pasado [es decir, las veladas literarias], es la que viene hoy a patrocinar y a plantar este joven árbol, que no arraigará sino con la protección generosa de nuestros compatriotas que no pueden ver con indiferencia los adelantos de su país (14).

La idea de la publicación estaba cifrada en que las muestras que allí se imprimían mezclaran lo "útil" con lo "dulce", en forma de artículos históricos, biográficos, descripciones del país, estudios críticos y morales. De esta manera, Altamirano anuncia que su maestro, Ignacio Ramírez, se encargaría de una serie de estudios sobre literatura, siguiendo el orden de sus lecciones como profesor de la Escuela Preparatoria; y Manuel Peredo se encargaría igualmente de la crítica teatral. Finalmente, dice Altamirano: "llamamos a nuestras filas a los amantes de las bellas 
letras de todas las comuniones políticas, y aceptaremos su auxilio con agradecimiento y con cariño" (15).

El proyecto funcionó tan bien que para la segunda época de la revista Altamirano agradece el reconocimiento que la gente hizo de la publicación. Agradece a todos los autores, sobre todo a los pertenecientes a otras ideologías distintas a la de los editores, el haber participado. Establece continuar en la misma línea una publicación "puramente literaria", "lejos de las cuestiones de la política". Así, espera que el amor a las letras se convierta en amor a la patria, y que todo esto impulse el "progreso material" y "moral" del país, conduciéndolos a la "grandeza" (17).

Sin embargo, en 1869, Altamirano debe suprimir la edición de su publicación. Dice que la empresa cierra ante "nuevos proyectos literarios" que ocupan a sus integrantes. Establece que su objetivo: impulsar las nuevas letras, ha sido conseguido a pesar de las dificultades que conlleva cualquier proyecto literario. Postula que la nueva generación es fuerte gracias, también, a ellos, a $E l$ Renacimiento, pues los jóvenes han seguido el ejemplo y han publicado otros diarios en diversos lugares del país. De esta manera, El Renacimiento puede desaparecer sabiendo que ha cumplido su tarea. El número está dedicado a la descripción de don Francisco Zarco, fallecido ese mismo año, y a la publicación de los capítulos finales de Clemencia, novela escrita por Altamirano; también se da noticia de la publicación de la obra en formato libro: "La belleza de la forma tipográfica hará que se disimule el poco mérito de nuestro trabajo" (20). Finalmente, promete una nueva publicación, literaria y filosófica, para el año 1870 , lo cual en muchos casos se convirtió en costumbre: finalizar una publicación sin perder de vista la nueva empresa. La revista cierra con la impresión de las despedidas redactadas por lectores, colaboradores y editores ${ }^{14}$.

El 15 de octubre de 1885 Altamirano lanzó El Liceo Mexicano, en cuya introducción establece que las empresas literarias, diarios y revistas, no logran subsistir por más de un año. A pesar de ello, dice, en la actualidad se presencia con optimismo la aparición de varias publicaciones. Asimismo, se empiezan a crear asociaciones juveniles literarias de suma importancia para el "adelanto intelectual" (22) de la patria. Es el caso de Liceo Mexicano Científico y Literario, dueño de la publicación en la que escribe Altamirano, que tiene como meta dar a conocer las creaciones de sus integrantes. Señala la existencia de otras organizaciones: el Liceo Hidalgo, el Liceo Morelos, y otros liceos en Oaxaca, Toluca, Aguascalientes, etc. Finaliza: "Sólo la savia del vigor juvenil puede mantener frondoso el árbol de la literatura nacional" (23). Dos años después del anterior saludo Altamirano, el 15 de octubre de 1887, vuelve a saludar desde El Liceo Mexicano. Dice que luego de dos años de publicación, empezando el tercero, solo caben las felicitaciones a los

${ }^{14}$ Acerca de este importante medio periódico, véase a Batis (1963) y Bedoya (2012). 
integrantes de la misma. A diferencia de lo sucedido con El Renacimiento, en donde las penurias económicas abatían a los coordinadores, aquí agradece al señor Ministro de Fomento, general don Carlos Pacheco, quien ha protegido al periódico, quien ha garantizado la impresión en la Imprenta de la Secretaría de Fomento, y por medio de él, el Liceo y la revista lograron establecer comunicación con numerosas corporaciones literarias y literatos de Europa y América; por fin, Altamirano cumplía, por lo menos en parte, su sueño de tener una publicación literaria apoyada económicamente, en este caso gracias a las políticas liberales de su gobierno.

\section{Edición y lectura crítica de la literatura}

Reconocido como militar, poeta, novelista, orador, historiador y político, es en la crítica literaria en donde sobresale el verdadero valor como intelectual de Altamirano. La crítica del ambiente cultural le permitió crear un instrumento para su magisterio intelectual: el artículo, la reseña y la revista o revisión. Aquellas formas escriturales pueden ser consideradas géneros periodísticos y críticos literarios sin parangón alguno en el México de entonces. No es en la poesía o en las notas costumbristas de su juventud, ni tampoco en la narrativa de su madurez en donde se halla el arma intelectual de Altamirano, sino en aquellos subgéneros periodísticos: mitad reseña y nota, mitad ensayo y crítica literaria, llamadas en aquel entonces como "revistas", o en términos más contemporáneos: "revisiones", revisiones de géneros literarios, de corrientes, de autores, de temas, etc. Pariente del ensayo impresionista, mezcla de estudio sistémico, combinaba lo más acabado de ambos. Gracias a este instrumento Altamirano volcó la lección patriótica en estilo literario. Por supuesto, nada de ello hubiese sido posible sin las condiciones objetivas ya presentadas hasta aquí: la conversación y el estudio en las veladas, y la materialización que procuraban las publicaciones periódicas.

Una de sus revisiones de mayor importancia se tituló: "Revistas literarias de México (1821-1867)" "15. Se trata de un texto dividido en cuatro partes que suman un poco más de cien cuartillas en formato libro. El primer apartado "Renacimiento de la literatura mexicana. Ojeada histórica" tiene un objetivo claro: establecer la historia literaria mexicana para concluir que México está preparada para dar inicio a la nueva generación de escritores, "Decididamente la literatura renace en nuestra patria" (1988': 29). Para establecer dicho "renacimiento", el autor dibuja el listado

15 La primera edición apareció en el folletín de La Iberia, a mediados de 1868. La segunda en formato libro, en México: Díaz de León y Santiago White, 1868. La tercera, también en formato libro, en México: T.F. Neve Imprenta, 1868 (se trata de la edición definitiva, utilizada para el presente estudio. Véase Altamirano 1988a). La cuarta edición, en formato libro, México: Biblioteca de Autores Mexicanos, 21, Imprenta de V. Agüeros Editor, 1899, dentro del volumen Obras de Ignacio Manuel Altamirano. Tomo I. (es la edición que más se conoce, sin embargo, es una edición reducida en su tercera parte. El editor eliminó pasajes y textos completos, además de juicios sustanciales de Altamirano). 
de los autores que formaron, en el principio, la base del edificio literario nacional. Una institución de hombres que solo abandonará la poesía ante la discusión política, de esta manera, unos tomarán la espada, otros se volcarán a la pluma del periodismo: "El fragor de la guerra ahogó el canto de las musas" (30). La relación de autores y obras está contextualizada en el marco histórico de los mismos: la guerra de invasión americana, las cuatro guerras civiles, la invasión francesa y la guerra contra el segundo imperio.

Le sigue la descripción y crítica de una segunda generación, conformada por hombres tales como Francisco Zarco, su maestro Ignacio Ramírez, Cardoso y Prieto (los tres últimos aún vivos en momentos en que Altamirano escribe la reseña). Para Altamirano, la propuesta literaria de estos autores sigue vigente y debe ser comparada - exagerando de manera consciente- con la obra de Quintana Roo, Heredia, Prescott, Irving, Olmedo y Bello. Asimismo, dice que las puertas de la literatura mexicana están abiertas para todo aquel que tenga la "voluntad" de ingresar. Ante tal tarea insta a todos los jóvenes escritores, tales como Riva Palacio y sus jóvenes discípulos.

La segunda entrega "Elementos para una literatura nacional", se detiene en el presente literario de su país, en donde lo político ocupa un segundo puesto, ya que están dadas las condiciones sociales para que se dé el crecimiento de lo literario. Altamirano comenta que existe un "público" que "recibe con placer", "lee con avidez" y "aplaude" las nuevas publicaciones (33). De esta manera, México está preparada para darle la bienvenida a la nueva literatura, al fin de cuentas siempre ha tenido material de "inspiración" en abundancia: la historia antigua mexicana, la dominación española, la naturaleza mexicana, las guerras de independencia, las guerras civiles y la época republicana.

En su idea de lo nacional se rehúsa a aceptar autores tales como Tomas Gage, Humboldt, Lovesterm y la señora Calderón, quienes han pintado "mentirosamente" a su país (guardadas las proporciones en el caso de Humboldt), o el caso específico de Pérez Escrich cuya novela La esposa mártir está atiborrada, para Altamirano, de inexactitudes geográficas. Así, los mexicanos no pueden correr el riesgo de que estas imágenes sean las que los den a entender, sino que ellos mismos deben decir quiénes son.

Paralelo a su trabajo crítico, Altamirano buscó la edición de materiales mexicanos en México. Asimismo, garantizó (hasta donde sus recursos se lo permitieron) el pago a los autores, por lo menos a aquellos que participaron en la publicación de sus medios de comunicación. Promocionó la crítica entre la obra y el lector a partir del papel que jugaron sus "Bibliografías" y la escritura de Prólogos, Reseñas y $\operatorname{Notas}^{16}$. De todo su trabajo como comentador de obras, literarias y no

16 Desde El Renacimiento, en el año 1867, y hasta El Diario del Hogar, en 1887, pasando por El Federalista, en los años 1880-1883, Altamirano se dedicó a publicar reseñas 
literarias, sobresale su Nota "María. Novela Americana por Jorge Isaacs", en la que apunta que nadie, ni siquiera en Europa o el mismo autor colombiano, creerá la forma en que tal obra se convirtió en "obra maestra" (191), pues a diferencia de las obras que llegan de España y Francia, casi siempre con muchos anuncios y estrépito, la obra de Isaacs no fue olvidada porque debajo de lo novelesco poseía "una teoría del porvenir atrevida y grandiosa; algo, ciertamente, como un decálogo filosófico o moral" (192). Su lectura le recordó la tragedia griega, sobre todo Esquilo y Sófocles, por lo menos en cuanto al "espíritu". Formalmente, dice Altamirano, le pareció "original", exactamente americanista, seductora y poética. Dice que su clave está en conjugar la verdad con el talento, y no en tramas imposibles o sentimientos altamente afectados. Rastrea sus antecedentes en Pablo y Virginia, Atala, Clara del Alba, Delfina y Werther. Para Altamirano, la obra es idílica ya que es la personificación de la poesía americana y su naturaleza en todo su esplendor descrita. En ella no hay nada abrupto como en Zola o en el realismo de Daudet y Balzac. Altamirano cuenta que la obra hace llorar a sus lectores y que es la lectura preferida de los que saben amar, porque en ella hay dolor, pero también pureza y virginidad ${ }^{17}$.

También está el caso de "Revista literaria y bibliográfica (1867-1882)"18, en la que Altamirano analiza la literatura pasada y contemporánea en aras de difundir la lectura de las nuevas producciones; o el título "Revista literaria (1883)"19, en la que se analiza la vida y obra de autores literarios contemporáneos para, finalmente, llamar la atención sobre el silencio de las revistas y los catálogos extranjeros sobre la producción bibliográfica mexicana. Piensa como causa la pobre circulación de

y estudios de autores tales como: Fernando Orozco y Berra, Florencio M. del Castillo, Ignacio Rodríguez Galván, Guillermo Prieto, entre muchos otros, por ejemplo, las reseñas de las obras: El cerro de las campanas de Juan A. Mateos, Calvario y tabor de Riva Palacio y Las flores del destierro de José Rivera y Río. Prologó por extenso las Fábulas de José Rosas Moreno, Versos de Ramón Rodríguez Rivera, Recuerdos de Adolfo Llanos y Alcaraz, El Escéptico de Vicente Morales, Pasionarias de Manuel M. Flóres, Viaje a oriente de Luis Malanco, La mina y los mineros de Pedro Castera, Poesías de Miguel Ulloa, El romancero nacional de Guillermo Prieto, y un largo etcétera.

${ }^{17}$ Existe edición de la novela que posee esta nota de Altamirano (y otros textos escritos por los discípulos del mexicano), lo que da cuenta de la alta recepción de la novela en México. Véase: Isaacs (1898).

18 Publicada en Primer almanaque histórico, artístico y monumental de la República mexicana, 1883-1884, publicado por Manuel Caballero. New York, México: The Chas. M. Green Co., 1883, pp. 75-89. Véase: Altamirano (1988a).

19 Publicado por primera vez en La República. Semana Literaria. México, tomo IV, núm. 12, 22 de julio de 1883, pp. 177-179; num 13, 29 de julio de 1883, pp. 93-199; num. 17, 26 de agosto de 1883, pp. 257-260; num. 18, 2 de septiembre de 1883, pp. 273-275, num. 19, 9 de septiembre de 1883, pp. 289-291; num 25, 21 de octubre de 1883, pp. 381382; num. 26, 28 de octubre de 1883, pp. 397-402. Véase: Altamirano (1988a). 
los mismos, pero sobre todo, la falta de un catálogo bibliográfico mexicano. La tarea que Altamirano se toma como propia es la realización de reseñas biobibliográficas semanales en las que comenta las obras, literarias y no literarias, de los mexicanos. Así, inicia su tarea con la reseña de materiales de instrucción primaria, los más importantes en palabras de Altamirano, pero también hace el análisis de obras históricas mexicanas, en donde llama la atención que el historiador mexicano, en contraposición al europeo, tiene muchos problemas en la consecución de las fuentes históricas, ya que no existen catálogos ni archivos. También analiza libros de poesía, incluso libros de Derecho Constitucional, novedades literarias hispanoamericanas, libros de geografía, etc.

Finalmente, relacionado con el tema de la difusión de los textos y la lectura, es clave el título "De la poesía épica y de la poesía lírica en $1870 " 20$, en el que Altamirano establece que el progreso de la literatura mexicana actual ha sido limitado a causa de tres razones: la falta de un público lector, las dificultades para la publicación y la falta de tiempo para que dicha literatura logre "renacer" totalmente. Sobre la primera causa el autor aclara que los "genios" (Homero, Dante, Cervantes) no necesitan de la simpatía del público, ya que sus obras son de tal magnitud que el lector posterior las hallará interesantes. Sin embargo, los autores principiantes, como lo son los pertenecientes a la generación mexicana de la cual Altamirano está hablando, necesitan de la simpatía de los lectores para animarse a seguir trabajando. Seguidamente, establece que la literatura ha sido apoyada por muy pocos, ya que los hombres que saben leer son una minoría, y de esa minoría la mayor parte, simplemente no lee, otros leen lo necesario para su trabajo en el "mundo de los negocios", otros porque le huyen a la lectura que no sea aquella de la rutina, y otros porque no cuentan con el dinero suficiente para comprar literatura. Comparados con el contexto norteamericano, dice, resulta que el progreso en México está obstruido por la ignorancia, de allí que sea un fin de la literatura la alfabetización de las primeras letras, hasta "remontarse a las sublimes esferas de la epopeya, de la filosofía y de la historia" (189).

\section{Traducción y universalismo literario}

Altamirano, que pidió "literaturizar" la nación mexicana, fue consciente de la importancia que tenía en esta tarea el conocimiento de las letras universales, en contra de la imitación servil, tal como lo expresó en sus revisiones literarias:

${ }^{20}$ Publicado por primera vez en entregas, en: El Federalista, México, 6 de marzo, 3 y 10 de abril, 15 de mayo y 5 de junio de 1871, dentro de la sección "Bosquejos", con el título de "La literatura en 1870". Segunda edición en El Domingo, México, 21 de abril, 12 y 19 de mayo, 16 de junio, 11 de agosto, 8,15 y 22 de septiembre y 6 de octubre de 1872 (se trata de la versión más completa y utilizada aquí: Altamirano, 1988a). 
No negamos la gran utilidad de estudiar todos las escuelas literarias del mundo civilizado; seríamos incapaces de este desatino, nosotros que adoramos los recuerdos clásicos de Grecia y de Roma, nosotros que meditamos sobre los libros de Dante y de Shakespeare, que admiramos la escuela alemana y que desearíamos ser dignos de hablar la lengua de Cervantes y de fray Luis de León. No: al contrario, creemos que estos estudios son indispensables; pero deseamos que se cree una literatura absolutamente nuestra, como todos los pueblos tienen, los cuales también estudian los monumentos de los otros, pero no fundan su orgullo en imitarlos servilmente (1988a: 37).

Como ejemplos de este movimiento, y en el contexto hispanoamericano, señala los nombres de Mármol, Echeverría, Arboleda y Pombo. La imitación, dice Altamirano, es un inconveniente para el "progreso" de lo literario, por ello se debe ser como Bello, quien demostró que se podía trascender la "forma" griega cantándole a América. En contraposición, la literatura nacional en México no impera porque sus autores están apegados a los preceptistas, porque siguen pensando que "la corrección del estilo" es lo "principal", cuando realmente lo es la confluencia, tanto de "la forma como [de] la idea" (1988a: 195).

De esta manera, paralelo a su trabajo de comentador de obras nacionales, Altamirano emprende la crítica de una serie de autores extranjeros, a partir de reseñas, notas y traducciones, tal como ya se ha expuesto aquí con el caso de María de Jorge Isaacs. Por su análisis pasan autores de renombre: Dickens, Manzoni, Daudet, Goethe, Schiller y Lessing. Acerca del primero realizó un estudio en El Renacimiento, firmado el 26 de enero de 1869, en el que relaciona la totalidad de las obras del inglés, sus empresas periodísticas y la actual fama que tiene en el mundo, sobre todo en Inglaterra y Estados Unidos, en donde es toda una "personalidad pública". Para Altamirano la obra de Dickens sobresale por la descripción moral de sus obras (a diferencia de las obra de los franceses). Se trata de un apóstol del progreso moral, dice Altamirano, para quien lo mejor que puede ocurrir es que Dickens sea leído en México y que sus obras sean "adaptadas" y no "imitadas":

En sus cuadros, no sólo retrata con la mayor fidelidad las costumbres inglesas, sino que encierra en ellos siempre una lección de la más sana y pura moral, dándoles así un interés de que carecen todas las copias fotográficas de costumbres, cuando no tienen por objeto la corrección de un vicio o la enseñanza de algo bueno y útil (1989: 9).

Los autores extranjeros dignos de ser comentados por Altamirano deberán cumplir, directa o indirectamente, sus postulados de "belleza", "utilidad" y "moralidad". Una obra debe ser bella para que sea leída, pero la belleza debe ser moral y sobre todo útil en la formación de la nación mexicana, debe ser modelo de comportamiento. Asimismo, de los textos traducidos no literarios sobresalen 
aquellos que tienen la literatura como fuente de estudio, por ejemplo: "Literatura alemana: Klopstock, Goethe" de E. Mennechet, que Altamirano tradujo y publicó en El Federalista, el 13 de agosto de 1871. Se trata de un texto acerca de la imitación que los alemanes hacen de las obras clásicas francesas, en el que se asegura que Lessing es el primero en reaccionar en contra de tal práctica; al tiempo que es el autor que permite la aparición de "maestros" tales como Klopstock, Goethe y Schiller. También sobresale el texto: "Literatura, crítica, biografía: Gotthold-Ephraim Lessing", se trata de la reconstrucción de la biografía del crítico alemán, hecha por Altamirano a partir de las biografías alemanas de DantzelGuhrauer y Stahr. Altamirano compuso el texto sobre el crítico para los no entendidos en la lengua alemana y publicó su nota, sin dejar de hacer comentarios sobre la importancia de la labor del crítico en el contexto mexicano, en La Tribuna, el 21 y 26 de enero de $1874^{21}$.

\section{La historia literaria y la idea de nación: el caso de la novela}

Existen noticias de que Agustín Pablo Pérez de Castro escribió los inicios de una historia literaria mexicana o hispanoamericana, pero hoy dicho material se encuentra perdido. De esta manera, el primer registro escrito de una especie de historia de la literatura mexicana data de 1755 , se trata del primer tomo de Biblioteca mexicana, repertorio bibliográfico de escritores coloniales, de Juan José de Eguiara y Eguren. El siguiente antecedente de la historia literaria mexicana aparece en el siglo XIX, en los años 1816, 1819 y 1821, en donde el proyecto de Eguiara y Eguren es completado por José Mariano Beristáin y Souza, en su: Biblioteca Hispanoamericana septentrional. Sin embargo, todos estos proyectos deben pensarse más como compendios bio-bibliográficos que como historias literarias. Lo mismo puede decirse del trabajo de José Zorrilla La flor de los recuerdos (1855) y del de Joaquín Baranda Discurso sobre la poesía mexicana (1866). Dado el anterior contexto, no es aventurado decir que solo en los trabajos de Altamirano se percibe, por primera vez, una conciencia histórica de lo literario: artículos, notas biográficas, notas bibliográficas, reseñas, prólogos, revistas o

${ }^{21}$ La nota se detiene en la descripción del ambiente religioso que envolvió los primeros años de vida del crítico alemán. Asimismo, describe la atmósfera del lugar en donde nació, Camenz, un lugar altamente conservador y religioso. Luego se detiene sobre los primeros estudios de Lessing, las dificultades económicas para ingresar y sostenerse en la Universidad, y su inicio como autor de teatro, lo cual no era deseado por sus familiares. Altamirano cuenta que en la Universidad, además de reconocidos amigos, Lessing conoce a los profesores Winkelmann y Kästner. Hace énfasis sobre la vida universitaria y de cómo ésta moldea su personalidad como crítico y estudioso: los idiomas, las lecturas, los profesores, etc. Luego relata los años como crítico literario y no como autor, ya que debía escribir para sobrevivir. Altamirano rescata que la obra de Lessing ha hecho que Macaulay lo llame el primero de Europa, en materia de crítica literaria. 
revisiones, ensayos y estudios. Existen en todos estos trabajos una crítica y una ordenación secuencial, histórica, de la literatura mexicana. Curiosamente, los textos fueron publicados en diversos periódicos y revistas literarias, entre 1868 y 1883 , esta última fecha año de publicación de la primera Historia crítica de la poesía en México de Francisco Pimentel, considerada por muchos como la primera historia literaria mexicana de nociones modernas.

En sus escritos, Altamirano da cuenta de los acontecimientos, los libros, las personalidades ilustrativas de la cultura, etc. Lo que al principio de este trabajo, de la mano de Gutiérrez Girardot, se denominó como "institución" literaria. Asimismo, en sus discusiones sobre la novela se encuentran los lineamientos de una "filosofía" liberal y progresista, realmente nacionalista, de Altamirano. Para el mexicano, la novela está llamada a abrir el camino de la cultura a las clases pobres, ya que instruye y deleita a quienes carecen de bibliotecas. La importancia de la novela para el proyecto de Altamirano es tal que su tercera revista está dedicada a la "producción literaria" cuya "lectura" es "más popular" (1988a: 39). En la actualidad, dice Altamirano en el temprano año de 1868: la novela no es un cuento imaginativo sin límite alguno, es un "género superior", en el cual es necesario apartar la fantasía y hallar:

En el fondo de ella el hecho histórico, el estudio moral, la doctrina política, el estudio social, la predicación de un partido o de una secta religiosa: en fin, una intención profundamente filosófica y trascendental en las sociedades modernas. La novela hoy suele ocultar la biblia de un nuevo apóstol o el programa de un audaz revolucionario (39).

Debe recordarse que lo anterior lo dice un hombre creyente en una sociedad altamente creyente, pero lo dice un hombre creyente, también, en el progreso y en la función cumplida por la educación y el estudio. Para este autor, la fábula novelesca ya estaba en las leyendas griegas y romanas además de las leyendas de caballería medieval. En su recorrido por los autores ejemplares, desde la Grecia antigua hasta su actualidad, resaltará los nombres de Scott, Richardson, Hugo, Balzac, Sue, Dumas, Karr y Dickens, por supuesto, además del de Goethe.

$\mathrm{Su}$ estudio sobre la novela lo hace preguntarse por las condiciones de producción de la misma. Por ello ve en la imprenta la "madre" de la novela y el periodismo, pues los otros géneros pudieron vivir de forma oral. Asimismo, establece que la época clásica produjo los gérmenes de la novela (Herodoto y la novela histórica, la Atlántida de Platón y la novela política, la Odisea y la novela de viajes, el Talmud, la Biblia y la novela religiosa, etc.), hasta Voltaire y Rousseau y la novela filosófica, y el Werther de Goethe, origen de un nuevo género: la novela romántica. Es en este momento en el que la novela surge nueva, sin límites, convirtiéndose en la "forma" que adopta "a todas las ideas y a todos los asuntos, haciéndose el mejor vehículo de propaganda" (48). Por ello Altamirano concluye: hoy la novela ocupa 
un lugar central en la vida intelectual y moral de las naciones, ella es el espacio donde se da la discusión filosófica, política, moral, etc. (lo mismo que buscó en un principio con las veladas), de allí su "utilidad" y "efectos benéficos" en la "instrucción de las masas" (48). Y con el mayor acento liberal Altamirano dictará:

La novela del siglo XIX debe colocarse al lado del periodismo, del teatro, del adelanto fabril e industrial, de los caminos de hierro, del telégrafo y del vapor. Ella contribuye con todos estos inventos del genio a la mejora de la humanidad y a la nivelación de las clases por la educación y las costumbres (48).

Incluso ve en la novela histórica una manera de escribir la historia de la nación. Finalmente, dice que la novela "amorosa" debe tener algo saludable, o por lo menos no tener "un veneno oculto". En sus palabas se nota claramente lo poco dispuesto que está a comparar en un mismo nivel la novela romántica con la histórica. En su reflexión, el autor se detiene y aclara que no es uno de aquellos que desea la "previa censura", al contrario, sabe de la necesidad social de la lectura de novelas, como disipador de la carga diaria; sin embargo, la idea de lo moral y lo útil se imponen, por lo cual concluye que para la juventud lo mejor es leer algo que posea cierto grado de virtud, el resto hace mal y corrompe a las generaciones ${ }^{22}$.

El poder que le relega a la novela lo impone como directriz a los nuevos autores. En esta línea de sentido compone el comentario a la obra Una rosa y un harapo, novela inconclusa del joven José María Ramírez, en la que Altamirano invita al escritor a terminarla y buscar los frutos económicos que tal tarea le puede traer. De esta manera se hacen un bien el autor y el público, dice Altamirano, ya que un escritor pobre no puede trabajar tan bien como alguien que no deba dedicar parte del tiempo de sus días a buscar el sustento. Altamirano le reprocha al joven escritor su gusto por Karr, en lugar de centrarse en una figura ejemplar como la de Hugo. Asimismo, aconseja cambiar de estilo, eliminar por completo su "fraseología" intelectual, que podría alejar a las masas, y le recuerda que el éxito de la novela depende del grado de instrucción que pueda formar en las masas, sobre todo en la mujer "porque es su género" (1988b: 77). Para explicar lo anterior trae a colación el ejemplo de la iglesia, que a partir del lenguaje sencillo de las parábolas logró

${ }^{22}$ Por ejemplo: el Wherter de Goethe "extravió muchas almas", igual las obras de Sand, Kock y La dama de las camelias de Dumas, hijo; por ello, dice Altamirano, una obra de amor debe contener una fuerte carga moral, incluso si la historia no resulta verosímil con la realidad. Así, hace advertir que para él la importancia de la novela radica en la educación que logra hacer de las masas, el puente entre el "pueblo pobre" y la minoría intelectual. La novela ocupa el lugar de las bibliotecas, tal como ya lo había hecho el periodismo, la canción popular y la tribuna, siendo quizás, más fuerte que los anteriores (56). Dado lo anterior, se comprende por ejemplo la importancia que el mexicano evidencia en la novela María de Isaacs. 
introducirse incluso en los "salvajes" y luego, una vez instruidos, la iglesia comenzó a predicarles, lo que conllevaba que el pueblo alcance un grado de cultura tal que puedan hablarles desde el sermón y la plática doctrinal y el discurso. De esta manera se debe proceder con la novela, apunta Altamirano, la novela debe ser sencilla porque incluso la clase media no tiene la capacidad para lecturas más cultas.

\section{Palabras finales}

Desde la emancipación, en 1821, México se desgastó en los azares de las batallas y los debates políticos, tan sólo en 1868 con el triunfo de la República se dieron las primeras condiciones reales de constitución de una institución, lo suficientemente fuerte para abanderar el proyecto de progreso nacional. En este momento se inscribe la acción cultural de un hombre como Ignacio Manuel Altamirano, que gracias al estudio sistémico de las letras y las ideologías pasó de ser un humilde indígena en una municipalidad del país, a ser ejemplo nacional, uno de los prohombres políticos más importantes de su país, y uno de los intelectuales más importantes del continente.

Brading (1995) considera necesario delimitar el significado del "nacionalismo" para que no pierda sentido y empiece a significar "cualquier cosa" relacionada con el "patriotismo", el "orgullo" o la "devoción". De esta manera, afirma que "El nacionalismo constituye un tipo específico de teoría política; con frecuencia es la expresión de una reacción frente a un desafío extranjero, sea éste cultural, económico o político, que se considera una amenaza para la integridad o la identidad nativas" (11), y es en este sentido que las presentes páginas entienden cada una de las actividades culturales de Altamirano; por ello sus constantes búsquedas de enseñanzas e inspiración para guiar el presente, así como su constante estudio de los episodios de la Independencia y las diversas luchas en contra de los "invasores": Estados Unidos y Francia. En este sentido, Altamirano desemboca en un tipo de intelectual distinto a sus contemporáneos, no es el político ni el periodista tipo Ignacio Ramírez "El Nigromante", su admirado maestro. Altamirano es, en todo el sentido de la palabra, y tal como lo expresa Brading (1991), un: "hombre de letras, de temperamento conciliador, tendente a la nostalgia romántica" (710), realmente un organizador de la vida cultural mexicana, al límite de agrupar a los autores en veladas y asociaciones, de fundar las revistas y otros medios de publicación de las obras de los jóvenes, al límite de apoyar materialmente la publicación, de dirigir en la corrección de los intentos de escritura de los jóvenes autores, al tiempo que crea un lector capacitado para dicha lectura. Paralelo a todo ello, es el redactor oficial del proceso, su historiador.

No es gratuita la presencia de Altamirano en los estudios del historiador Brading, o las alusiones que hizo de él Alfonso Reyes (1991): "Altamirano, indio puro, fue el más grande en su tiempo y es uno de nuestros valores universales, y su genio atractivo se manifestó prácticamente en todos los géneros del oficio literario y 
en todos los órdenes del trato humano" (428). La figura de Altamirano es clave en el entendimiento de la realidad literaria del continente durante el siglo XIX, al lado de Bello y Sarmiento, pero pobremente estudiado en contextos distintos al mexicano ${ }^{23}$.

Paralelo al trabajo realizado por Altamirano, es de rescatar su fuerte dosis crítica en cada una de sus páginas. Sus obras trascienden el impresionismo, y desde el siglo XIX abordó la literatura desde postulados teóricos claros, al tiempo que conjugó el análisis histórico de los autores y las obras. En este sentido es clave el conocimiento que Altamirano tuvo, en el momento de criticar, de la obra de Aristóteles, Horacio, Luzán, Boileau, Taine, Sainte-Beuve y Madame de Staël24.

Es tal el valor de Altamirano como promotor de la literatura de su país que según Reyes Navares (1951), hasta 1887, todo aquel que participaba de la literatura nacional mexicana había sido presentado por el mexicano, ya que: "Altamirano se puso, pues, a la tarea de hacer que los otros escribiesen, y que la gente leyera sus obras, y que los periódicos las comentaran, y que los editores las buscasen y las pagasen bien" (xx). Sin embargo, de lo producido en los años en que Altamirano dirigió el proceso literario mexicano es poco lo que se puede resaltar, literariamente hablando, el día de hoy. Pero gracias a su trabajo se sentó las bases para el futuro, por ejemplo, para el momento en que su discípulo Justo Sierra se consagra ante la vida literaria. La propuesta de Altamirano también posibilitará la reunión de sus discípulos y amigos en el proyecto El Renacimiento, segunda época, en 1894. Proyecto en el que se dará a conocer, entre otros, Manuel Gutiérrez Nájera, y proyecto que resultará ser el antecedente directo de Revista Azul, quizás la mayor apuesta mexicana por el modernismo literario del continente.

Además de lo ya expuesto hasta aquí, y como consecuencia de todo ello, de su gran valor como intelectual, es necesario indicar que Altamirano asumió varios cargos en la Suprema Corte de Justicia y en el Ministerio de Fomento, fue profesor en la Escuela Nacional Preparatoria, en la de Derecho y en la Escuela Nacional para Maestros, y creador de la Escuela Normal para Profesores de la ciudad de México. Asistió a diversos congresos, representando a México, en Suiza e Italia. En 1889, a sus 55 años, fue nombrado cónsul general en España, igual en Francia. En 1892

${ }^{23}$ Por ejemplo, en el contexto colombiano las investigaciones sobre Altamirano son, por poco, nulas. Tan sólo Gómez (2011) quien redactó un capítulo de libro dedicado a la comparación del mexicano con Tomás Carrasquilla, en la relación literatura nacional y literatura regional. Desde esta perspectiva, resulta singular el trabajo de Chris Nacci (1970), de nacionalidad italiana, redactado en inglés, sobre el intelectual mexicano.

${ }^{24}$ Es tal el conocimiento que Altamirano tiene de las propuestas teóricas de su época que Erasto (1997) comenta que en 1890 apareció La evolución de los géneros en la historia literaria de Brunetiére, quien hubiera estado satisfecho con el desarrollo que Altamirano ya le había dado a la novela en sus críticas. 
viajó a Italia y el 13 de febrero de 1893, a los 58 años, murió en San Remo de tuberculosis pulmonar.

\section{BIBLIOGRAFÍA}

ALtAMIRANO, Ignacio Manuel.

1958 Historia y política de México (1821-1882). Colección: El liberalismo mexicano en pensamiento y en acción. México: Empresas Editoriales S.A.

1986 "Poesías". Obras Completas. Tomo VI. Salvador Reyes Nevares (sel. y notas). México: Secretaría de Educación Pública.

1988a "Escritos de literatura y arte. Tomo 1". Obras Completas. Tomo XIV. José Luis Martínez (sel. y notas). México: Secretaría de Educación Pública.

1988 b "Escritos de literatura y arte. Tomo 2". Obras Completas. Tomo XIV. José Luis Martínez (sel. y notas). México: Secretaría de Educación Pública.

1989 "Escritos de literatura y arte. Tomo 3". Obras Completas. Tomo XIV. José Luis Martínez (sel. y notas). México: Consejo Nacional para la Cultura y las Artes.

1992 "Diarios". Obras Completas. Tomo XX. Catalina Sierra (pról. y notas). México: Consejo Nacional para la Cultura y las Artes.

1995 Paisajes y leyendas. Tradiciones y costumbres en México. Intr. de Jacqueline Covo. México: Porrúa.

BATIS, Huberto.

1963 Índices de El Renacimiento. Semanario literario mexicano (1869). Estudio Preliminar. México: Universidad Nacional Autónoma de México, Centro de Estudios Literarios.

BEDOYA SÁnCHEZ, Gustavo Adolfo.

2012 "Origen y límites del crítico en dos publicaciones periódicas literarias. El Renacimiento (México: 1869-1894) y El Nuevo

Tiempo Literario (Colombia: 1903-1915, 1927-1929)". Acta Literaria. Concepción: Universidad de Concepción, no 44, pp. 135151.

BRADING, David.

1991 Orbe Indiano. De la monarquía católica a la República criolla 1492-1867. México: FCE.

1995 Los orígenes del nacionalismo mexicano. México: Ediciones Era. 
ERASTO CORTÉS, Jaime.

1997 "Altamirano: perfiles de un crítico". Homenaje a Ignacio Manuel Altamirano (1834-1893), en Manuel Higashi y Alejandro Higashi (eds.). Veracruz: Instituto de Investigaciones Lingüístico-Literarias, Universidad Veracruzana, pp. 137-143.

GIRÓN SOL, Nicole.

1997 "Altamirano en Cuautla". Homenaje a Ignacio Manuel Altamirano (1834-1893), en Manuel Higashi y Alejandro Higashi (eds.). Veracruz: Instituto de Investigaciones Lingüístico-Literarias, Universidad Veracruzana, pp. 21-48.

GÓMEZ GARCÍA, Juan Guillermo.

2011 "El problema de la nación y la región en dos clásicos de la literatura hispanoamericana: Altamirano-Carrasquilla", en Intelectuales $y$ vida pública en Hispanoamérica. Siglos XIX y XX. Medellín: Universidad de Medellín, Universidad Nacional de Colombia, pp. 175-231.

GONZÁLEZ RAMÍREZ, Manuel.

1936 Altamirano. Biografias populares. s.c.: Ediciones de La Universidad Nacional.

GUTIÉRREZ GIRARDOT, Rafael.

1989 Temas y problemas de una historia social de la literatura hispanoamericana. Bogotá: Ediciones Cave Canem.

ISAACS, Jorge.

1898 María. Novela Americana. Con un prólogo de J. M. Vergara y Vergara y juicios de Ignacio M. Altamirano, Guillermo Prieto y Justo Sierra. París: Casa Editorial Garnier Hermanos.

NACCI, Chris N.

1970 Ignacio Manuel Altamirano. New York: Twayne Publishers.

REYES, Alfonso.

1991 "Resumen de la literatura mexicana (siglos XVI-XIX)", en Obras Completas, Tomo XXV. México: FCE, pp. 397-464.

REYES NEVARES, Salvador.

1959 "Prólogo: vida de Altamirano", en Obras literarias completas. Nevares: Ediciones Oasis, S. A., pp. XI-XXV.

RUIZ MEZA, Víctor.

1976 Altamirano. Bocetos juveniles. Toluca: Dirección del Patrimonio Cultural y Artístico del Gobierno del Estado de México, Editorial Libros de México.

SÁNCHEZ CASTRO, Alejandro.

1964 Altamirano como militar. México: s.e. 